\title{
BIZPROJET: THE CO-DESIGN OF AFFINITIES AND SKILLS SEARCH-ENGINE - TEAM BUILDING AROUND AN INNOVATIVE PROJECT: NEW KNOWLEDGE SHARED?
}

\author{
Evelyne Lombardo, (Kedge Business School and LSIS, CNRS, France), Evelyne.lombardo@kedgebs.com \\ Serge Agostinelli, (LSIS, CNRS), serge.agostinelli@lsis.org \\ Marie Ouvrard, marie-ouvrard@univ-amu.fr \\ Sophie Arvanitakis, (LSISI, CNRS, sophie.arvanitakis@lsis.org) \\ Marielle Metge, metge@univ-tln.fr \\ Grant Linscott, Kedge Business School, grant.linscott@kedgebs.com
}

\begin{abstract}
The related research aims to develop and test in the future two technological components that enable managers to form a project team. The first component proposes a search-engine of performance and affinities based upon the personalities and interpersonal skills of individuals. The second component proposes a search-engine of selection and recommendation for the establishment of a successful project team. Both components will be integrated into a web service to promote innovative use, in terms of obtaining human resources that match a team project, and also in the management of one's career. Beyond the computing aspects, the project raises a crucial issue for cognitics and information technology: That is the compatibility of Social and Human Science and ICT Science of Technology and information and communication for knowledge management models. We present in this paper exploratory analysis prior to the implementation of these two search engines and the bases and methods used for the characterisation of business performances, together with the interpersonal and professional skills necessary for the functioning of a team.
\end{abstract}

Keywords: Bizprojet, affinity, search-engine, team practice, competence, representation

\section{INTRODUCTION}

The PACA Labs project called Bizprojet, focuses on the design of an Internet Service that matches the practices of supply and demand with the offering amongst corporate managers, project managers, business actors and independent resources. The contribution of the research allows, on one hand, the understanding and the management of the implicit expectations in communication between the principals in the establishment of a project team. So that they can, on the other hand, easily (thanks the search engine developed) select compatible resources (business actors) according to two categories of human resource skills: relational and methodological. The technical skills of "business" however, are not addressed in this context of "characterization" for this part of the research. These contributions allow the development of affinity and performance search-engine software with a recommendation search-engine that draws from a library of business profiles depending on the expectations for a project team.

\section{POSITION OF THE PROBLEMS}

The scientific goals of our research are situated between Social and Human Science and Informational and Communicational Technologies. This situation is recognised today as essential to technological innovation, as can be clearly seen by the increasing number of initiatives that aim to develop service applications based on the use of personal digital data (Facebook, Twitter, Google + ) or professionals (Linkedln, Viadéo, Xing) and user profiles.

However, these profiles are like bottles in the sea, nothing guarantees that they will be read by the right person, and in particular, the good business manager. Furthermore, rarely is the profile information which allows an estimation of skills different from those associated with the job, and yet nevertheless they are often the determining factor in the success of a team: If the team was understood to be the source of the innovation, then the hierarchy is perceived as the custodian of the knowledge. (McKinlay, 2002). In a community of practice (Wenger, 1998) the status results 


\section{Issues in Information Systems}

Volume 15, Issue I, pp. 434-441, 2014

from the expertise and from the participation of an individual. So, the tacit knowledge becomes infinitely more precious than the formal codification of explicit knowledge (McKinlay, 2002).

From here on, the first challenge is for us to know the way the manager expresses the relational and methodological skills necessary for the establishment of a working team according to a project to be implemented. The second challenge is the MMI (Man-machine interaction) with the increasing importance of the consideration of the users and thus the interface and the interaction man - machine, that is to say the specific human factors that are going to allow for recruitment or establishment of a team.

The first question arises from the nature of the terrain and from an observation: with the increase of roles associated with the World Wide Web, the offer of service providers and the project proposals multiply. For the company Nodalys, the question was how to join an intelligent marketplace offering the mechanisms of a secured transaction in a collaborative management platform. The idea is to propose the services of collaborative sourcing with the design and realisation of Informational and Communicational Technologies (TIC) projects. The project is under the supervision of a trusted third party.

From the operational point of view, it was a question of knowing how to structure and code both an affinity based personality and performance search-engine, and a selection and recommendation search-engine for a specific project.

The first challenge is for us to know the way the manager expresses the relational and methodological skills necessary for the establishment of a working team according to a project to be implemented. The second challenge is the MMI (Man-machine interaction) with the increasing importance of the consideration of the users and thus the interface and the interaction man - machine, that is to say the specific human factors that are going to allow for recruitment or establishment of a team.

These two search-engines demand a clarification of methodologies and analytical tools that:

A) Bring forth the relational skills with these objectives:

- To produce a personalised relational profile with its strong and weak points;

- To propose a group of persons who have the capacity to work together;

- To establish a network of professional relations around a project from the relational skills; in teams of more than three members (Neergaard and Madsen, 2004).

As it is often the case in the projects based on a complex innovative technology, strong links cohabit with weak links (Chabaud and Condor, 2009).

B) Set up a facility that aids the decisions in the construction of a project team with these objectives:

- To produce a group profile of affinities that matches a specific project;

- To propose an organisation of the team, according to the skills of each of the members.

\section{FRAMEWORK}

\section{Representation}

Our theoretical corpus finds its source in two simple ideas. The representation which we have of a job or a project orients our way of interacting with the other members of a team; the persons who share the same representation of their activities and their actions will find it easier to work together. Three dimensions characterise communities of practice and can be applied to the project teams of innovative projects (Chanal 2000 citing Wenger 1998)

- A form of mutual commitment in the representation where the members of a project team are collectively engaged in their actions, which they negotiate the sense of with others;

- A common project (the innovative project), the representation of which evolves over time and which creates relations of mutual responsibility between the members of the project; 


\section{Issues in Information Systems}

Volume 15, Issue I, pp. 434-441, 2014

- A shared directory which develops little by little and which can include physical media (models, prototypes), documents (specifications, documents of a project), terms or concepts, but also stories, myths, symbols.

Our theoretical approach guides to the central question: how to know if two professionals share the same representation of a project? Two possible responses are: Observe them in their practices and manners; or, listen to them speaking about what they do. It is this second option that was chosen and of course we considered how to limit the subjectivity of the material. The position which we adopt here suggests that the ordinary activities are constituted with methods to make analyzable: Practical actions, practical circumstances, the common representation knowledge of social structures, and practical sociological reasoning; (Garfinkel, 2007). This position presents two principles: the individuals act according to the meanings which they construct; the meanings build themselves through interactions (Goffman, on 1988).

The way that an individual keeps what he experiences in memory, then outputs is a form of representation that authorises the transformation or the repetition of an action in similar circumstances. The representation thus has a structure which allows action by taking into account professional rules and the ways of implementing them, but it also establishes a communicative structure which makes it tellable and understandable for all. The representation is thus based on the reflexive character of the daily activities in the common practices (constructed meanings) and the situations of interaction (the communications). It is this reflexive character of the communication that for us, give the social character to the representation. The descriptions which we make of our actions report the genesis of the connected representations and it is what allows us to identify and/or to examine their individual or collective occurrence.

In the collective or social representation, the individual is thus active in the reconstruction of the social reality. The representation is then the product and the process of a mental activity by which an individual or the group reconstitutes the reality in which it is confronted and attributes to it a specific meaning (Abric, 1994, p. 13).

\section{Relational Skills}

The notion of relational skills has a utilitarian connotation in the relation to others (Camus, 2011). It has a dimension of social interaction within a professional activity. The expectations of this interference of somebody oblige the other to negotiate the edges of a relational framework, thus defining the status of each one of us and the interference levels (Milburn, 2002). By bounding the rights and the duties of everyone, the relational skill establishes an added value of legitimisation of the interference of everyone within the framework of a working team. In other words, it is essential to the professional skill of the team, to stop in a practical way, the recognition of a professional independent: that of project manager, contributor or expert. The relational skills exceed the personal aspects of each member of the team. These relational skills cannot only be defined by inter-relational links or from a privileged communication arriving through an authority or by the influence of leadership. It is for us, a set of procedures implemented by the individuals so to make the framework of ordinary activities understandable and acceptable by the others. It also organises the shared meanings and favours the interaction between members of a team.

\section{Subjectivity of the discourse}

The subjectivity of the discourse bases itself on two aspects. The first one is a matter of the difficulty which exists in translating a discourse into computing terms essential to the realisation of a search-engine. The second, concerns the translation of the explicit senses clarified in the discourse. In computing, to give a sense to a data set is a common activity. The computer processing depends on the initial coding and on the way the code reconstructs the form of reality. The coding is thus a form of making sense of the data and this process of sensemaking gives a sense of the human-machine interaction. (Russell and al ., 1993) This concept, stemming from research in MMI, is used today to understand the construction of the reality and the apprehension of information by the individuals and groups (Dervin and al., 2003), but also, to understand the link that it exists between human behaviour and an organisational structure in which he acts (Weick, on 1995). This sensemaking process is considered to be a form of constructing a reality in the form of a continuous sense of accomplishment that arrives when people build retrospective meaning from situations in which they find themselves. 


\section{METHODOLOGY}

The subjectivity is characteristic of semantic differences which aim at creating and at comparing certain aspects of the meaning of a "concept" (be it a word, sound, facial expression, picture). The idea is that any concept, word, expression used in a discourse can be situated on a measurement axis with two opposing poles (Menahen, 1968, $\mathrm{p}$. 451).

It is from these differentiators (Osgood and al., 1967) that we built our first level of criteria, that arranges categories that are, for us, the building blocks that will allow us to find similarities or differences between the various discourses. Thus, we bring forth essential, useful, redundant or contradictory material that is a common repository for the realisation of a project. These criteria are a category above the most qualitative and subjective aspects of the discourse, to a more operational and quantitative semantic category.

From such criteria, our discourse analysis is based upon Cognitive Discourse Analysis (CDA Ghiglione and al., 1998) and Propositional Discourse Analysis (PDA Ghiglione and Blanchet, 1991) in which the each unit is a phrase. We have identified the key terms that correspond to the ideas containing the essential meanings and have grouped the themes that most represent the values that allow the establishment of a project team.

Finally, this analysis is coupled with a study of representations that "obviously has a central importance in human communication" (Goody, 2006, p. 20). There are three aspects of this concept that are interesting in the establishment of a methodology of analysis of what is said and written about an expressed word: When the word represents an object; when words speak of an action; when the words move away from objects or actions to express comments about what is happening.

In fact, if the analyses of these discourses allow us to identify the elements that build the symbolic function and its implementation, we still have to build the collection tool and to implement it in the search-engines. What we are looking for are the "right questions" that bring forth the core and peripheral elements. For this we rely on a classic study of representations from a characterization questionnaire (Verges, 2001) and a similarity analysis (Aissani and Bonardi, 1991). The overall hypothesis is the existence of a collective hierarchy of items that characterise the definition of a project team. This is to locate items by their hierarchy and to highlight what are the "salient values" (the most representative), but also "organising values" of the representation, that is to say, the values that are essential to the definition of a project team. The method presented here does not concern the entire project. The use of the method is limited to characterisation of the representation of managers as to what is the project concept.

At the first stage of discourse analysis we demonstrated that the axis of the semantic differential of the project idea was between two concepts. On the one hand, there are projects that are established, and on the other, projects that are innovative. Of course, as we mentioned above, the discourse is never as clear-cut, but are situated between these axes. This observation has also a strong impact on our experiment because we were asked to adapt the characterization questionnaire method.

We have opposed these two concepts (established/innovative) from the theoretical positions. The discourses translate the importance of action plans for the implementation of the project. This is the classic analytical perspective of problem-solving (Newell and Simon, 1972) that designs the realisation of a task as executing a plan of action determined in advance. This concept was the basis for the construction of CAL (Computer-Assisted Learning) or ITS (Intelligent Tutoring Systems) in which the operation of the subject, like that of a computer, was likened to a machine to process symbolic information; this information processing taking place in reference to a decision tree. However, we have translated the most opportunistic (innovative) aspects by situated actions (Suchman, 1987). With this in mind, the individual is considered as a system to be researched constantly for information resulting from the interaction with its (his/her) environment.

This semantic differentiation has allowed us to build a first interview guide intended to acquire results on the relevance of the questions of the representation of a project for the managers. Two research questions and two hypotheses are tested in this phase of exploratory discussions with the managers. The first question asks whether the managers (bosses, project leaders), have common formulations concerning the definition of a project and a project team. This question has to first assume that managers make the distinction between an innovative project and a established project. The second question seeks to know what kind of expectations the managers may have in the creation of a project team regarding the methodological and interpersonal skills. The second hypothesis here is that the managers are able to define the expected characteristics of expected skills to build a team around a project, but 


\section{Issues in Information Systems}

Volume 15, Issue I, pp. 434-441, 2014

more importantly, that they are able to distinguish between specific skills required for an established or innovative project.

Our method is semi-directive. It is comprehensive and gives free rein to the choice of answer made by the respondents, with their words and details that makes sense according to them. An oral questionnaire (Blanchet, 1985) was assigned with the issues fixed in advance in a predefined order, of which we expected accurate answers. The interviews were recorded and transcribed. The questionnaire is divided into five levels: (1) The definition of the concept of the project with open-ended questions; (2) The nature of the project with nine items to classify; (3) The characteristics of the team with nine items to classify; (4) The project methodology and the role of project members consisting of nine items to rank for three types of project stakeholders: the project leader, the contributor, the expert; (5) The behavioural and interpersonal skills, also organized in nine items to rank for three types of project stakeholders. The questionnaire was given to fourteen business leaders or managers.

In the first part of the interview, we examined the concepts: projects, established, innovative, team / group, a team member. In analysing the responses recorded and transcribed, we distinguished the three levels mentioned by Goody (2006). In addition, we separated the recurrences in the explanations of the concepts and the distinctions. In the analysis of short exchanges of the "open" questions, we were able to consolidate recurring significant items, or semes, (the smallest units of meaning recognized) as "the same" and "different" (from those recurring) delivering a new idea.

The second part of the interview is based upon the characterisation questionnaire with the theoretical postulate of the existence of a collective prioritisation of themes of the survey (Flament, 1994). The questionnaire that was completed by fourteen managers seeks to identify the values that have a high salience, those that are important when building a team. This is to identify the skills expected by their proximity to the project concept.

The questionnaire consists of a list of items whose number is a multiple of three, for example nine: Three items are innovative, three items are neutral, and three items are established. It asks, firstly, whether the interviewee chooses the three items most characteristic of an innovative project, it then asks the interviewee to choose from the remaining six items the three strongest characteristics of an established project. With the method presented by Verges (2001), two questionnaires were necessary, but here our departing axiom was the logic of the semantic differential. The three innovative items must at one end of the axis, with the three established items at the opposing end, with the middle three being neutral. Each innovative item is then coded 1 to 3: 1 if it has been chosen as the most innovative, each established item is coded from 9 to 8: 9 if it was chosen as the most established.

In our version of the characterisation questionnaire, the fourteen managers interviewed did not follow the instructions to select three items and three from the remaining six. Citing that the same skill may have aspects, both innovative and established, according to their personality, they took back all the items to make the second choice. Therefore, an item can be both potentially classified by the manager as innovative and established, we established the number of times an item can be selected as 28 (the absolute sum of the number of times the same item could be chosen).

We do not have below all the responses to the items, but only those concerning levels 1 and 2: the definition of the terms and the nature of the project. By intersecting the semes classified from the discourse analysis (corresponding to the answers from the open questions from level 1 and the items from level 2), we can make three "shared" assertions from the proposals made in the form of items series level 1: (1) The objectives of the project are set at the beginning; (2) The project creates something new; (3) The project meets specific deadlines. Two other assertions seem to be corollaries: (1) Throughout the course of the project, it is necessary to make progress points, audits; (2) The financial framework of the project should be fixed. However three major questions remain: (1) Will the people who will work on the project be complementary? (2) Must the characteristics of the project be defined a priori? (3) Will the outcome of the project provide a basis for other upcoming projects?

It was very clear from the responses that there were no significant differences in ethical beliefs amongst MBA and MS-CIS graduate students. It should be noted that in both cases the students had not received formal training related to computer ethics within their program of study, though in both cases the topic was covered in sections within their curriculum. The curriculum for the MBA students is changing next year to include a formal course in business ethics that will include information technology related topics. 


\section{Issues in Information Systems}

Volume 15, Issue I, pp. 434-441, 2014

Based upon the results of our study, we concluded that significant differences existed between male and female computer information systems students in their ethical beliefs. Though as noted previously, there was a small sample population of female students. This is significant because it supports the industry study gender differences that show that software piracy and hacking tend to be more prevalent amongst males than females.

\section{RESULTS AND CONCLUSION}

In our experience the subject is the "project" and the question was how the words would represent the "project" and its variations. The definition of the project was described in the interviews as the realisation of an idea, the established aspects are the ways we put in place to achieve this idea. The innovative aspects are defined as the knowledge that enables our idea to bring something new to what exists on the market. The interview quotes show that a concept of the project is associated with an idea, the concept of established is associated with means while innovation is associated with novelty. For a manager ' $\mathrm{X}$ ', the project is to find a niche and do something you love, the established aspect can be found in finance, good people ... and the innovative aspect in that which does not exist on the market ... With these two examples, but also with other interviews, we find that the project is associated with an idea, and the established aspects relevant to human or material resources while innovative aspects relevant to novelty.

This observation is paradoxical, because when managers streamline their position and talk about the project, they assert that a project is something that is both established and innovative and that one doesn't exist without the other. Anyway, we considered these phrases as the characteristics of ways of thinking about reality.

The words also speak of the action as having produced, producing or prior to producing a result. The difference between group work and teamwork, verbs and expressions used, give us information on what the managers expect of the team surrounding a project:

- 'A team is established as in sports teams, whilst a group has no structure, everyone is working without rules, it is the method that makes the difference'

- The group is not homogeneous, people lead and people follow, there are a group of individuals that we do not necessarily know'

- In a team, each member has a job, there is a sense of coherence and complementarity between individuals'

- 'In the group there is a leader who energises the group while in the team, everyone has a few responsibilities. The influence of each person creates a dynamic.'

Here, we observe that teamwork should be toward established project, but there is a paradox. The team is established with the idea of homogeneity, with clearly identified positions, with complementarities between individuals with a shared responsibility, but in the group it is a leader who energizes. Therefore, the team can be identified by the means, rules or method. However, this finding rises for us, two questions:

- 'Is teamwork is a barrier to innovation? Indeed, for the manager innovation does not have anything to do with an established project.'

- 'With an established project team, the team members do not need the concept of the project because it was the Captain (sports) that provides the structure of the project?'

In fact, if in the field of research it is easy to differentiate teamwork and work (Proulx, 1999) and the work in groups and teams (Chatelain and Grange, 1999). It seems that organisational values representing the concept of a project team that should include the concepts of team and group are not prominent.

Finally, the discourse that moves away from the objects or actions to comment on the main subject gives a greater understanding:

- 'Write a project in a participatory manner, it is a motivation for writing, formalisation and reflection'

- 'To be part of a team one must know how to listen, how to recognize one's own mistakes, give advice, and do not only listen, but participate' 


\section{Issues in Information Systems}

Volume 15, Issue I, pp. 434-441, 2014

- 'A project is even better conducted when it is carried strongly within us, it's what belongs to us and that which corresponds to the project, and we will live it'

- 'Being part of a team that is known to hold some recognised talent.'

When these comments are organised around semantic principles, they can organize, build new generalisations, create new meanings, and organize our analysis in semantic categories. It is this work of deciphering, developing lists, tables in tree structures, which enable us in the implementation phase of it to develop the interface for entering parameters and thus give shape to conceptual thinking of the concept of a project team.

Concerning this part of the questionnaire, taking into account the discourse analysis, we found that seven out of fourteen subjects did not make the distinction between innovative project and an established project. Three of the seven, who made the distinction, we believe, only made it because we proposed to them to do so. Of the seven subjects who did not make the distinction, four strongly justified the failure to make the distinction. The common argument was: In a project, there is always an innovative part that would exist as a way of carrying out the project and there must be intrinsically an established part. This has challenged us to the point to consider that the distinction between these two parts is not valid, and should not be included in the test questionnaire online for future managers.

\section{REFERENCES}

1. Agostinelli, S. (2003). Les nouveaux outils de communication des savoirs (p. 210). Paris : L'Harmattan.

2. Aissani, Y., \& Bonardi, C. (1991). Évolution différentielle des éléments d'une représentation sociale : les apports de l'analyse de similitude. L'année psychologique, 91(3), 397-417.

3. Camus, O. (2011). La notion de compétences relationnelles : une conception utilitariste de la relation à l'autre. Communication \& Organisation, 40, 127-140.

4. Chabaud, D., \& Condor, R. (2009). La formation des équipes entrepreneuriales : une étude exploratoire. Revue internationale P.M.E. : économie et gestion de la petite et moyenne entreprise, 22(1), 81-102.

5. Chanal, V. (2000). Communautés de pratique et management par projet : A propos de l'ouvrage de Wenger (1998) Communities of Practice : Learning, Meaning and Identity. M@n@gement, 3, 1-30.

6. Blanchet, A. (1985). L'Entretien dans les sciences sociales : l'écoute, la parole et le sens (p. 289). Paris : Dunod.

7. Proulx, J. (1999). Le Travail en équipe (p. 128). Quebec : Presses Universitaires du Quebec.

8. Chatelain, Y., \& Grange, T. (1999). Travailler en groupe avec les nouvelles technologies de l'information et de la : communication (p. 160). Paris : L'Harmattan.

9. Chanal, V. (2000). La structuration d'un projet d'innovation par la communication électronique. Perspectives en management strategique, AIMS (p. 25).

10. Denis, M. (1989). Image et cognition (p. 284). Paris : PUF.

11. Dervin, B., Lois, F.-W., \& Lauterbach, E. (2003). Sense-making methodology reader : selected writings of Brenda Dervin (p. 397). New York : Hampton Press.

12. Fitzpatrick, E., \& Askin, R. (2005). Forming effective worker teams with multi-functional skill requirements. Journal of Computers \& Industrial Engineering, 48, 593-608.

13. Flament, C. (1994). Structure, dynamique et transformation des représentations sociales. In J.-C. Abric, (Ed.) Pratiques sociales et représentations, (pp. 37-57). Paris : Presses Universitaires de France.

14. Mideler, C., Garel, G., \& Giard, V. (2006). Management de projet et gestion des ressources humaines. In J. Allouche (Ed.), L'encyclopédie de la gestion des ressources humaines (2e ed., pp. 1001-1014). Paris : Vuibert.

15. Garel, G. (2003). Le Management de Projet (p. 122). Paris : Editions La Décrouverte.

16. Garfinkel, H. (2007). Recherches en ethnométhodologie (p. 480). Paris : PUF / Quadrige ( $1^{\circ}$ éd. 1967).

17. Ghiglione, R., \& Blanchet, A. (1991). Analyse de contenu et contenus d'analyses. Paris : Dunod.

18. Ghiglione, R., Landré, A., Bromberg, M., \& Molette, P. (1998). L'analyse automatique des contenus (p. 154). Paris : Dunod.

19. Gilles Garel (2011), Le Management de Projet, Paris, Editions La Décrouverte.

20. Goffman, E. (1988). L'ordre de l'interaction. In Y. Winkin (Ed.), Les moments et leurs hommes (pp. 186230). Paris : Seuil/Minuit.

21. Goody, J. (2006). La peur des représentations (p. 308). Paris : La Découverte.

22. Izard, M., \& Smith, P. (1979). La fonction symbolique : essais d'anthropologie (p. 346). Paris : Gallimard. 


\section{Issues in Information Systems}

Volume 15, Issue I, pp. 434-441, 2014

23. Jodelet, D., Viet, J., \& Besnard, P. (1970). La psychologie sociale, une discipline en mouvement (p. 470). Paris : Mouton.

24. Loilier, T. (1999). Équipes-projets et stratégies technologiques de l'entreprise : vers des configurations d'innovation. Finance Contrôle Stratégie, 2(1), 49-74.

25. McKinlay, A. (n.d.). The limits of knowledge management. New technology, work and employment, (13), 76-88.

26. Menahen, R. (1968). Le différenciateur sémantique. L’année psychologique, 68(2), 451-465.

27. Mideler, C., Garel, G., \& Giard, V. (2006). Management de projet et gestion des ressources humaines. In J. Allouche (Ed.), L'encyclopédie de la gestion des ressources humaines (2e ed., pp. 1001-1014). Paris.

28. Milburn, P. (2002). La compétence relationnelle : maîtrise de l'interaction et légitimité professionnelle. Revue Française de Sociologie, 43(1), 47-72.

29. Neergaard, H., \& Madsen, H. (2003). Knowledge-intensive entrepreneurship in a social capital perspective. Journal of small business and enterprise development, 10(4), 426-434.

30. Newell, A., \& Simon, H. A. (1972). Human problem solving (p. 920). Englewood, N.J. : Prentice-Hall.

31. Osgood, C. E., Suci, G., \& Tannenbaum, P. (1967). The measurement of meaning (p. 360). Chicago : University of Illinois Press.

32. Russell, D. M., Stefik, M. J., Pirolli, P. L., \& Card, S. K. (1993). The cost structure of sensemaking. In S. Ashlund, K. Mullet, A. Henderson, E. Hollnagel, \& T. White (Eds.), INTERCHI 93 - Conference on Human Factors in Computing Systems (pp. 269-276). Amsterdam : IOS Press

33. Suchman, L. A. (1987). Plans and Situated Actions : the problem of human-machine communication (p. 203). Cambridge, MA USA : Cambridge University Press.

34. Vergès, P. (2001). L'analyse des représentations sociales par questionnaires. Revue française de sociologie, $42(3), 537-561$.

35. Weick, K. E. (1995). Sensemaking in organizations (p. 231). New York : Sage

36. Wenger, E. (1998). Communities of Practice: Learning, Meaning, and Identity (p. 318). Cambridge: Cambridge University Press.Abratt, R., Nel D., \& Higgs, S. N.(1992). An examination of the ethical beliefs of managers using selected scenarios in a cross-cultural environment. Journal of Business Ethics, 11(1), 2935.

37. Weick, K. E. (1995). Sensemaking in organizations (p. 231). New York : Sage

38. Wenger, E. (1998). Communities of Practice: Learning, Meaning, and Identity (p. 318). Cambridge: Cambridge University Press. 